\title{
BMJ Open Anticholinergic and sedative drug burden in community-dwelling older people: a national database study
}

\author{
Catherine J Byrne, ${ }^{1}$ Caroline Walsh, ${ }^{1}$ Caitriona Cahir, ${ }^{1}$ Cristín Ryan, ${ }^{2}$ \\ David J Williams, ${ }^{3}$ Kathleen Bennett ${ }^{1}$
}

To cite: Byrne CJ, Walsh C, Cahir C, et al. Anticholinergic and sedative drug burden in community-dwelling older people: a national database study. BMJ Open 2018;8:e22500. doi:10.1136/ bmjopen-2018-022500

- Prepublication history and additional material for this paper are available online. To view these files, please visit the journal online (http://dx.doi. org/10.1136/bmjopen-2018022500).

Received 20 February 2018

Revised 8 May 2018

Accepted 7 June 2018

Check for updates

(C) Author(s) (or their employer(s)) 2018. Re-use permitted under CC BY-NC. No commercial re-use. See rights and permissions. Published by BMJ.

${ }^{1}$ Division of Population Health Sciences, Royal College of Surgeons in Ireland, Dublin, Ireland

${ }^{2}$ School of Pharmacy and Pharmaceutical Sciences, University of Dublin Trinity College, Dublin, Ireland ${ }^{3}$ Department of Geriatric and Stroke Medicine, Royal College of Surgeons in Ireland and Beaumont Hospital, Dublin, Ireland

Correspondence to Dr Catherine J Byrne; catherinebyrne@rcsi.com

\section{ABSTRACT}

Objectives The Drug Burden Index (DBI) tool quantifies individual exposure to anticholinergic and sedative medications. The DBI has been internationally validated against adverse health outcomes in older people. DBI exposure has not been reported in the Irish older population. This study aimed to: (1) develop a list of drugs with clinically significant anticholinergic and/or sedative effects (DBI medications) relevant to Ireland; (2) examine, using the DBI formula, the prevalence of exposure to DBI medications in Irish older people and (3) explore patient factors associated DBI exposure.

Design A cross-sectional national pharmacy claims database study.

Setting Community setting using the General Medical Services (GMS) scheme pharmacy claims database maintained by the Health Service Executive Primary Care Reimbursement Services.

Participants Irish older individuals (aged $\geq 65$ years) enrolled in the GMS scheme and dispensed at least one prescription item in 2016 ( $n=428516)$.

Main outcome measures Prevalence of exposure to $\mathrm{DBI}$ medications and patient factors associated with DBI exposure.

Results $282874(66 \%)$ of the GMS population aged $\geq 65$ years were exposed to at least one DBI medication in 2016. Prevalence of exposure to DBI medications was significantly higher in females than males (females $71.6 \%$ vs males $58.7 \%$, adjusted $\mathrm{OR} 1.65,95 \% \mathrm{Cl} 1.63$ to 1.68 ). Prevalence of DBI exposure increased progressively with the number of chronic drugs used, rising from $42.7 \%$ of those prescribed 0-4 chronic drugs to $95.4 \%$ of those on $\geq 12$ chronic drugs (adjusted OR 27.8, 95\% $\mathrm{Cl} 26.7$ to 29.0). The most frequently used DBI medications were codeine/paracetamol combination products (20.1\% of patients), tramadol (11.5\%), zopiclone $(9.5 \%)$, zolpidem (8.5\%), pregabalin $(7.9 \%)$ and alprazolam $(7.8 \%)$

Conclusions The majority of older people in Ireland are exposed to medications with anticholinergic and/or sedative effects, particularly females and those with multiple comorbidities. The high use of low-dose codeine/paracetamol combination products, Z-drugs and benzodiazepines, suggests there are opportunities for deprescribing.

\section{INTRODUCTION}

Medications with anticholinergic and sedative effects carry significant risks of adverse events

\section{Strengths and limitations of this study}

This was a large national cross-sectional study of exposure to medications with anticholinergic or sedative effects (Drug Burden Index (DBI) medications) in Irish community-dwelling older people.

- A consensus list of $\mathrm{DBI}$ medications available in Ireland was developed and used to establish the prevalence of exposure in a highly representative population.

- The main limitations of this study result from the constraints of using pharmacy claims data, which do not include information about the clinical indication for prescriptions, and therefore, it is not possible to assess the appropriateness of DBI medications.

- All medications dispensed were included in the analyses, but it is not possible to confirm whether the medications were consumed.

in older people. ${ }^{1}$ However, these medications are used to treat a range of conditions that occur commonly in later life such as mental illness, sleep disturbances, nausea, pain and urinary incontinence. ${ }^{2}$ In older patients, particularly those with comorbidities, this may result in an additive anticholinergic and sedative burden. ${ }^{3}$ Anticholinergic medications have a range of adverse effects including dry mouth, blurred vision, constipation and urinary retention (peripheral effects), as well as dizziness, confusion, reduced concentration and delirium (central effects). ${ }^{4}$ Drugs with sedative effects also cause central nervous system adverse effects, including sedation, memory and psychomotor impairment, and impairment of balance control. ${ }^{5-7}$ Older people are more sensitive to these adverse effects due to age-related pharmacokinetic and pharmacodynamic changes. ${ }^{1}$ In community-dwelling older people, anticholinergic and sedative drugs have been linked with an increased risk of falls, ${ }^{8}{ }^{9}$ functional impairment $^{1011}$ and cognitive decline. ${ }^{12}{ }^{13}$ Evidence to support the efficacy of some anticholinergic and sedative medications often does not 
justify their risks in older people. ${ }^{14}{ }^{15}$ Evidence suggests that deprescribing of some of these medications, such as psychotropic drugs, may result in positive patient health outcomes. ${ }^{16-18}$ Therefore, reducing the inappropriate use of these medications in older people is an important public health issue.

Several tools have been developed to evaluate exposure to anticholinergic or sedative medicines. One such tool is the Drug Burden Index (DBI), which is unique when compared with other tools, as it accounts for both cumulative medication exposure and for the patient's dose. ${ }^{19}$ The DBI uses the drug monograph to determine whether a drug has clinically significant anticholinergic or sedative effects by considering the pharmacology and side-effect profile of the drug. The minimum efficacious dose, which is a key component of the DBI calculation, is determined according to the country-specific approved product information. ${ }^{2}$ An accumulating body of evidence supports the validity of the DBI tool in terms of predicting functional impairment in older people, with observational studies from different international settings independently associating DBI exposure with poorer physical function, 71920 frailty, ${ }^{21}$ falls ${ }^{15}{ }^{22}$ healthcare utilisation ${ }^{1523}$ and in some studies, mortality. ${ }^{1523}$

In order to develop strategies to minimise the inappropriate use of anticholinergic and sedative medications in older people, a reliable measure for describing the magnitude of the problem and the identification of targets for improved prescribing of these medications is necessary. However, the prevalence of exposure to anticholinergic and sedative drugs using the DBI tool has not been reported in the Irish older population. Additionally, the list of DBI medications and their minimum effective daily doses needs to be tailored for the specific country of investigation, as the availability of drugs and their minimum recommended daily dose may differ between countries due to regulatory factors as well as factors that may influence drug effects such as genetics, ethnicity, diet and environment. ${ }^{2}$ Furthermore, a complete list of DBI medications and minimum effective daily doses to use for screening purposes, which could be adapted to the specific country and periodically updated, has not been published. This study aimed to: (1) develop a list of drugs with clinically significant anticholinergic and/ or sedative effects (DBI medications) and their corresponding minimum recommended daily doses in older people relevant to Ireland; (2) examine, using the DBI formula, the prevalence of exposure to DBI medications in Irish community-dwelling older people and (3) explore patient factors of age, gender and comorbidity associated with increased exposure to DBI medications.

\section{METHODS}

\section{Study population and design}

This was a cross-sectional national pharmacy claims database study in the community setting. Data from the Irish Health Service Executive (HSE) Primary Care
Reimbursement Services (PCRS) pharmacy claims database were used to identify the study cohort: older people (aged 65 years and over) enrolled in the General Medical Services (GMS) scheme in Ireland, who had been dispensed at least one prescription in 2016. The HSE-PCRS reimburse pharmacists for the provision of prescription medication in Ireland, through a number of schemes, including the GMS scheme. The GMS database represents the single largest pharmacy claims dataset in Ireland. The GMS scheme provides mainly free health cover (a small copayment on medicines was introduced in 2010) for those eligible and covers approximately $40 \%$ of the general Irish population. Eligibility for the GMS scheme is means tested, with a considerably higher threshold for those over 70 years of age, ensuring approximately $80 \%$ of this age group are considered eligible for the scheme. ${ }^{24} 25$

Medicines in the HSE-PCRS pharmacy claims database are coded according to WHO Anatomical Therapeutic Chemical (ATC) classification system. ${ }^{26}$ Permission to use the anonymised HSE-PCRS data for research purposes was obtained from the HSE-PCRS.

\section{Measuring anticholinergic and sedative exposure}

The DBI tool was used to calculate cumulative exposure to medications with clinically significant anticholinergic and/or sedative effects (DBI medications) dispensed from 1 January to 31 December 2016. For this analysis, all DBI medications (with the dose information) were identified using relevant ATC codes and subsequently extracted from the pharmacy claims database.

\section{List of DBI medications}

Medications with potential anticholinergic and/or sedative effects, available in Ireland, were identified by reviewing several drug monographs ${ }^{27-31}$ and previously published studies. ${ }^{19} 2032$ This list was then refined according to definitions developed by consensus between a pharmacist (CJB) and a clinical pharmacologist (DJW) as follows: A medication was considered to have clinically significant anticholinergic effects if the pharmacological profile of the drug included anticholinergic activity (blocking activity at muscarinic receptors) as well as a side-effect profile consistent with anticholinergic effects listed in the product literature. A medication was considered to have clinically significant sedative effects if drowsiness (or a similar description) was listed as a common (occurring in $>1 / 100$ and $<1 / 10$ users) or very common (occurring in $>1 / 10$ users) adverse effect in the product literature. Topical preparations without significant systemic effects were excluded as per previous studies. ${ }^{19} 20$

The minimum effective daily dose was decided by consensus between two pharmacists (CJB, CW) after independent review of drug monographs. ${ }^{27-31}$ The following assumptions were made in determining the minimum effective daily dose:

i. The minimum effective daily dose in older people was used when stated; otherwise, the minimum effective daily adult dose was used. 
ii. For drugs initiated at a low dose and titrated to effect, the minimum effective daily maintenance dose was used.

iii. For drugs with several indications, and when doses varied depending on the indication, the minimum effective daily dose across all indications was used, except for opiates where the minimum effective daily dose was based on the analgesic dose.

iv. For drugs available alone and in combination with other drugs, the minimum effective daily dose for the anticholinergic/sedative drug alone was used to define the minimum effective daily dose for the anticholinergic/sedative drug in the combination product.

v. For analgesic drugs with different doses for breakthrough pain and chronic pain, the minimum effective daily dose for chronic pain was used.

vi. For drugs administered on an 'as needed' basis, the minimum effective daily dose was the minimum effective single dose multiplied by the minimum number of times the dose is normally repeated in 24 hours.

vii. For drugs administered by more than one route, the minimum effective daily dose for the oral route (or the most commonly used route if not administered orally) was used as the reference dose. The reference dose was converted to an equivalent dose for other available routes of administration based on reported conversion factors or bioavailability data. ${ }^{27} 283031$

\section{Calculating DBI exposure}

Total DBI exposure for each individual was calculated as the sum of exposure to any DBI medication dispensed in 2016 using the following equation ${ }^{19}$ :

$D B I=\sum D /(\delta+D)$ where $D$ is the daily dose taken by the individual patient, and $\delta$ is the minimum effective daily dose for that drug. The daily dose taken by the individual patient for each DBI medication was estimated by multiplying the strength and total quantity dispensed in 2016, and then normalising by dividing by 365 days. ${ }^{15}$ DBI exposure was also quantified for each patient over 1 year including only chronic DBI medications, defined as at least three prescription items dispensed in the year for the same fourth-level ATC code (eg, N02AJ) ${ }^{33}$

\section{Statistical analysis}

Exposure to DBI medications was categorised dichotomously as unexposed $(\mathrm{DBI}=0)$ and exposed $(\mathrm{DBI}>0)$. Prevalence rates and associated 95\% CIs for GMS eligible patients aged 65 years and over with at least one prescription dispensed in 2016 (DBI exposure) were calculated. Logistic regression was used to examine the association between DBI exposure and the following patient variables: age at first dispensing in 2016 (categorised into 65-69 (reference), 70-74, 75-79 and $\geq 80$ years), gender (male (reference), female) and number of coprescribed chronic medications over the year (categorised as 0-4 (reference), 5-7, 8-11 and $\geq 12$ chronic medications). Chronic medication was defined as receiving at least three prescription items dispensed in the year with the same second-level ATC code (eg, N02), relating to only the following first-level codes: A (alimentary tract and metabolism), B (blood and blood-forming organs), C (cardiovascular system), G (genitourinary system and sex hormones), H (systemic hormonal preparation, excluding sex hormones and insulins), L (antineoplastic and immunomodulating agents), $\mathrm{M}$ (musculoskeletal system), N (nervous system), R (respiratory system) and $\mathrm{S}$ (sensory organs), and excluding those on the denominator of the DBI exposure. ${ }^{33} 34$ Adjusted ORs and 95\% CIs were computed. Statistical significance at $p<0.05$ was assumed. Statistical analyses were conducted using SAS V.9.4 (SAS Institute).

\section{Patient and public involvement statement}

No patients were involved in setting the research question or the outcome measures, nor were they involved in developing plans for design or implementation of the study. No patients were asked to advise on interpretation or writing up of results. There are no plans to disseminate the results of the research to study participants or the relevant patient community.

\section{RESULTS}

The final list of DBI medications and their minimum effective daily doses (master DBI list) is provided in online supplementary table S1. This list included 156 medications ( 15 with anticholinergic effects only, 87 with sedative effects only and 54 with both anticholinergic and sedative effects). Online supplementary table S2 shows the DBI medications listed in one of the original DBI studies in the USA, ${ }^{20}$ but not included in the master DBI list. Online supplementary table S3 shows the DBI medications included in the master DBI list but not included in the original DBI study in the USA. ${ }^{20}$

In total, $282874(66 \%)$ of the 428516 GMS eligible population aged 65 years and over in receipt of any claim during 2016 received at least one claim for a DBI medication. The prevalence of chronic DBI exposure was $54.0 \%$. Median (IQR) DBI score over the year was 0.52 (0.11-1.03).

Table 1 shows the prevalence of patients with DBI exposure in 2016 by a range of patient characteristics. Females were significantly more likely to have DBI exposure compared with males (females $71.6 \%$ vs males $58.7 \%$, adjusted OR 1.65, 95\% CI 1.63 to 1.68). Prevalence of DBI exposure increased noticeably with the number of chronic drugs used, rising progressively from $42.7 \%$ of those prescribed $0-4$ chronic drugs receiving a DBI prescription to $95.4 \%$ of those on $\geq 12$ chronic drugs (adjusted OR 27.81, 95\% CI 26.72 to 28.96). Those aged 80 years and over had a significantly higher prevalence of DBI exposure than those aged $<80$ years $(\geq 80$ years, $71.5 \%$ vs $<80$ years, $63.5 \%$ ). In multivariate analysis, the association between increasing age and DBI exposure was diminished (adjusted OR $0.82,95 \%$ CI 0.81 to 0.84 ). 
Table 1 Prevalence of patients aged 65 years and over dispensed at least one DBI medication prescription in 2016

\begin{tabular}{|c|c|c|c|}
\hline \multirow[b]{2}{*}{ Patient-level fixed effects (n) } & \multirow{2}{*}{$\begin{array}{l}\% \text { dispensed a DBI } \\
\text { prescription }\end{array}$} & \multicolumn{2}{|l|}{ OR $(95 \% \mathrm{Cl})$} \\
\hline & & Unadjusted & Adjusted \\
\hline \multicolumn{4}{|l|}{ Sex } \\
\hline Male (185 938) & 58.7 & 1.00 & 1.00 \\
\hline Female (242 578) & 71.6 & 1.78 (1.75 to 1.80$)$ & 1.65 (1.63 to 1.68$)$ \\
\hline \multicolumn{4}{|l|}{ No of chronic drugs } \\
\hline $0-4(153960)$ & 42.7 & 1.00 & 1.00 \\
\hline $5-7(113614)$ & 66.4 & 2.65 (2.60 to 2.69 ) & 2.67 (2.63 to 2.71$)$ \\
\hline 8-11 (102 682) & 83.9 & 6.96 (6.82 to 7.09$)$ & 7.03 (6.89 to 7.17$)$ \\
\hline$\geq 12$ (58 260) & 95.4 & 27.63 (26.55 to 28.76$)$ & 27.81 (26.72 to 28.96$)$ \\
\hline \multicolumn{4}{|l|}{ Age (years) } \\
\hline 65-69 (96 804) & 63.5 & 1.00 & 1.00 \\
\hline 70-74 (109 118) & 62.4 & 0.95 (0.94 to 0.97$)$ & 0.85 (0.83 to 0.87$)$ \\
\hline 75-79 (93 300) & 65.3 & 1.09 (1.07 to 1.11$)$ & 0.81 (0.80 to 0.83$)$ \\
\hline$\geq 80$ (129 294) & 71.5 & 1.44 (1.42 to 1.47$)$ & 0.82 (0.81 to 0.84$)$ \\
\hline
\end{tabular}

DBI, Drug Burden Index; n, number of patients.

Table 2 shows the 10 most frequently used DBI medications by Irish older people in 2016. Codeine and tramadol were the most commonly used medications with sedative effects $(20.1 \%$ and $11.5 \%$ of patients, respectively). Of the 383641 codeine prescriptions dispensed in 2016, $98.9 \%$ were for codeine/paracetamol combination products, of which $54.6 \%$ were for low-dose codeine products (codeine/paracetamol $8 \mathrm{mg} / 500 \mathrm{mg}$ per tablet), $6.9 \%$ were for medium-dose codeine products (codeine/ paracetamol $15 \mathrm{mg} / 500 \mathrm{mg}$ per tablet) and $38.5 \%$ were for high-dose codeine products (codeine/paracetamol $30 \mathrm{mg} / 500 \mathrm{mg}$ per tablet). Prochlorperazine and hyoscine butylbromide were the most commonly used medications

\begin{tabular}{|c|c|c|}
\hline Medication & $\begin{array}{l}\text { Anticholinergic/sedative } \\
\text { effects }\end{array}$ & $\%$ patients \\
\hline Codeine & Sedative & 20.1 \\
\hline Tramadol & Sedative & 11.5 \\
\hline Zopiclone & Sedative & 9.5 \\
\hline Zolpidem & Sedative & 8.5 \\
\hline Pregabalin & Sedative & 7.9 \\
\hline Alprazolam & Sedative & 7.8 \\
\hline Diazepam & Sedative & 6.5 \\
\hline Escitalopram & Sedative & 5.9 \\
\hline Prochlorperazine & Anticholinergic + sedative & 5.9 \\
\hline Mirtazapine & Sedative & 4.8 \\
\hline
\end{tabular}

*Prevalence calculated by the number of patients dispensed at least one prescription for a DBI medication divided by the total number of patients dispensed at least one prescription in 2016. DBI, Drug Burden Index. with anticholinergic effects $(5.9 \%$ and $4.6 \%$ of patients, respectively).

Figure 1 shows the frequency of DBI drug classes dispensed to Irish older people in 2016. Anxiolytics/ hypnotics and antidepressants were the most frequently prescribed drug classes of DBI medications $(25 \%$ and $24 \%$ of DBI prescriptions dispensed in 2016, respectively). Of the 1264078 anxiolytic/hypnotic prescriptions dispensed in 2016, 52.5\% were for benzodiazepines and $47.4 \%$ were for Z-drugs (zopiclone, zolpidem and zaleplon). Of the 1211319 antidepressant prescriptions, $47.3 \%$ were for selective serotonin reuptake inhibitors, $16.8 \%$ were for tricyclic antidepressants, $16.7 \%$ were for serotonin norepinephrine reuptake inhibitors and 19.2\%

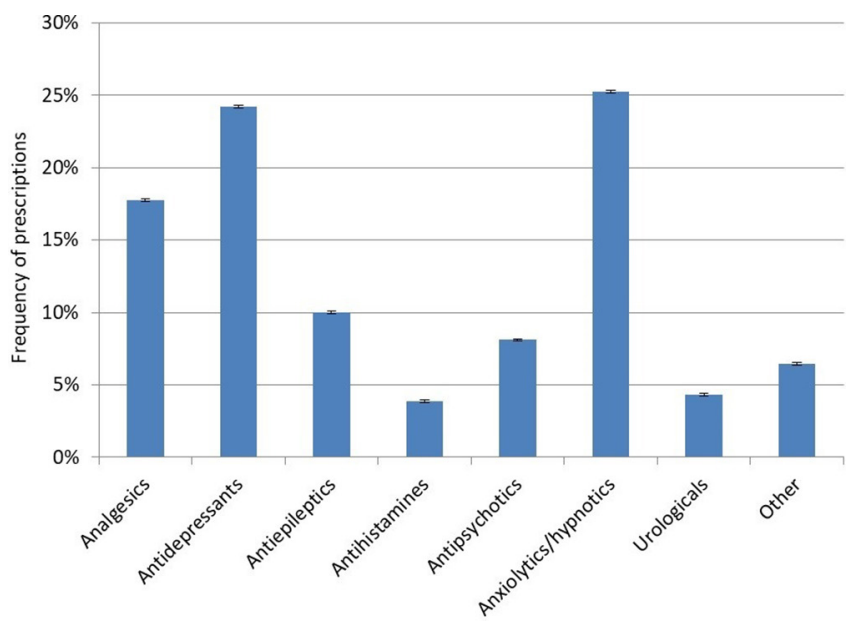

Figure 1 Percentage and 95\% Cls of anticholinergic and/ or sedative medication prescriptions dispensed by drug class in Irish older patients in 2016. Other=anti-Parkinson drugs, cardiovascular drugs, gastrointestinal drugs and muscle relaxants. 
were for other antidepressants (mirtazapine, phenelzine and trazodone).

\section{DISCUSSION}

This study found that the majority of older people in Ireland are exposed to medications with anticholinergic and/or sedative effects, particularly females and those with multiple comorbidities. A lower prevalence of exposure to DBI medications of $43 \%$ was reported in a previous population study of older people living in New Zealand, of similar size and methodology to the current study. ${ }^{15}$ Other studies of DBI exposure conducted in Australia, USA and Europe, with smaller cohorts of older people in various settings, have demonstrated a prevalence ranging from $20 \%$ to $79 \% .^{20} 213536$ This variability may be related to different definitions used to identify anticholinergic and sedative medications, specific sociodemographic or health status characteristics of participants, and differences in medication access and use across different settings and countries. ${ }^{2}$ Further, prevalence rates calculated for the current study included DBI medications dispensed on an 'as needed' basis. There is no consistency in terms of the inclusion or exclusion of 'as needed' medications in previous studies, which may also explain the variability in prevalence rates reported.

This current study found that female patients and patients with high comorbidity burdens, who are more likely to be very old (80+ years), all appear to be particularly vulnerable to exposure to DBI medications, which is consistent with the literature. ${ }^{15}$ Numerous studies have reported greater use of psychotropic drugs and analgesics by women compared with men. ${ }^{37-40}$ Possible reasons for a greater use among women include increased willingness to seek medical care, increased likelihood of women to perceive and report mental illness or pain, and general practitioner (GP) prescribing bias. ${ }^{41}{ }^{42}$ It has been shown that women are more likely to receive a prescription for a psychotropic drug during a GP consultation compared with men. ${ }^{37}$ Targeted efforts to reduce inappropriate prescribing of these medications in vulnerable older women are therefore needed.

In the present study, exposure to medications with sedative effects was considerably higher in older people compared with exposure to medications with anticholinergic effects. This is likely to be due to the frequent use of anxiolytic/hypnotic drugs, antidepressants and opioid analgesics. Similar patterns of use have been noted in cohorts of older people living in Finland, ${ }^{36}$ Australia ${ }^{43} 44$ and the USA. ${ }^{45}$ However, older aged people in Ireland appear to have considerably higher rates of use of codeine products and tramadol than their counterparts in Finland, according to a national population study in Finland of similar design to the present study. ${ }^{23}$

Examination of the most frequently used DBI medications (table 2) suggests there may be opportunities for deprescribing of DBI medications in older Irish people. The high use of low-dose codeine/paracetamol combinations is of particular concern. It is known that codeine doses of at least $30 \mathrm{mg}$ are required for analgesia. ${ }^{46}$ At this dose, a small but statistically significant increase in the analgesic effect of codeine/paracetamol combinations compared with paracetamol alone has been shown. ${ }^{46} 47$ However, there is a lack of pharmacological evidence to support the analgesic benefit from using low-dose codeine combination analgesics. ${ }^{48}$ Combining low doses of codeine with paracetamol is likely to bring minimal analgesic benefit, but will increase the risk of adverse effects. ${ }^{49}$ The most frequently prescribed codeine combination product in our study contained $8 \mathrm{mg}$ of codeine and $500 \mathrm{mg}$ of paracetamol per tablet. Thus, at the maximal dose of two tablets (16 mg/1000 mg codeine/paracetamol), the quantity of codeine would not achieve doses close to the minimum effective dose of codeine required for analgesia. Yet, these products will still induce the adverse effects experienced with codeine, including constipation, nausea, dry mouth, dizziness and drowsiness. ${ }^{50}$ Further, the use of codeine in older people has been associated with an increased risk of falls and hip fracture $(60 \%$ increased risk $),{ }^{51}$ which highlights the need to limit its use. ${ }^{52}$ Therefore, use of a paracetamol alone product, rather than a combined low-dose codeine/paracetamol product, may be more appropriate for some patients.

The high use of hypnotic Z-drugs and anxiolytic benzodiazepines (alprazolam and diazepam) is also noteworthy. Widespread use of benzodiazepines and Z-drugs has been reported in other European countries. ${ }^{53} 54$ These drugs should be used with caution due to their adverse effect profile, such as drowsiness, confusion, impairment of memory and incoordination, which can be particularly problematic in older people. ${ }^{55}$ Both benzodiazepines and Z-drugs have been associated with problems in older people including an increased risk of injurious falls and hip fracture, and cognitive impairment. ${ }^{14}{ }^{17}$ It is, therefore, recommended that these drugs be avoided in older people and, where appropriate, discontinuation under appropriate supervision is widely advised. ${ }^{17}{ }^{56}$ It has been shown that discontinuation of benzodiazepines and Z-drugs in community-dwelling older people is possible, without adverse events attributable to discontinuation, and may be associated with improved health outcomes, such as a reduction in the risk of falls and improvements in cognitive functioning. ${ }^{165758}$ A meta-analysis of interventions to reduce benzodiazepine and Z-drug use in older people demonstrated the beneficial effects of consultations and education of both prescribers and patients followed by a supervised withdrawal. ${ }^{59}$

\section{Strengths and limitations}

The present study was a large national study of DBI exposure in community-dwelling older patients in Ireland. The study design enabled examination of the variation in DBI exposure between patients in a highly representative population. A consensus list of DBI medications was developed, which may be of use for future studies using the DBI tool. 
The authors acknowledge the following limitations. These largely result from the constraints of using pharmacy claims data in this study. Information about the clinical indication for prescriptions is not available in pharmacy claims data, and therefore, it is not possible to assess the appropriateness of DBI prescriptions. DBI prescribing may not always be inappropriate. The prescription may be justified for clinical reasons, after balancing risk and benefit in conditions of uncertainty. Nevertheless, given that DBI medications have been associated with adverse events in older people, the observed high prevalence of DBI prescribing suggests that a significant amount of prescribing could be improved. In addition, pharmacy claims data do not include medications purchased over the counter (OTC). However, there is no incentive for GMS patients to buy medications OTC, as most of these items are available on prescription for a small copayment, and therefore, the risk of bias is expected to be low. All medications dispensed were included in the analyses, but it was not possible to confirm whether the dispensed medications were consumed and for how long. Therefore, the DBI calculations may not reflect true exposure. However, the results reflect prescribing practice in terms of intention to prescribe. There is also the possibility of socioeconomic bias, particularly in the 65-69years age group, as only $40 \%$ of this population is covered under the GMS scheme, which over-represents more socially deprived individuals. However, approximately $80 \%$ of those aged $\geq 70$ years are covered for medications under the GMS scheme, and therefore, socioeconomic bias in these patients would be low. Another notable limitation involves the list of DBI medications used in this analysis, which, although determined by consensus, may be associated with interpretation bias leading to an overestimation or underestimation of the prevalence of DBI exposure. There is no gold-standard definition to describe medications with clinically significant anticholinergic or sedative effects, and therefore, the clinical validity of our selection of drugs may be limited by this. Finally, the master DBI list provided in this study (online supplementary table S1) was based on medications and dosages relevant to prescribing in Ireland. Therefore, there may be medications available in other countries that are not on this list, and there may be medications on this list that are not available in other countries. The minimum effective dosages applied refer to prescribing in Ireland. Therefore, while the master DBI list provided could be used as a starting point in other countries, adaptation to the local setting in terms of availability of drugs and dosage is necessary.

\section{Implications for policy and practice}

The results of this present study highlight the need for interventions to reduce the inappropriate use of medications with clinically significant anticholinergic or sedative effects in older people in Ireland. In particular, the high use of low-dose codeine/paracetamol combination products, Z-drugs and benzodiazepines, suggests that interventions to alert prescribers and patients about the risks associated with these drugs in older people should be a priority. Due consideration should also be given to the importance of regular medication reviews, with a particular focus on older females and those with multiple comorbidities.

In practice, the DBI may be useful as a screening tool for older patients, to identify those patients with high exposure, which may compromise their physical and cognitive functioning. ${ }^{60}$ Such patients are likely to be eligible for deprescribing interventions such as medication review. ${ }^{60}$ A previous intervention study showed that collaborative pharmacist-led medication review with the GP can reduce the prescribing of sedative and anticholinergic medications in older people, resulting in a significant decrease in the DBI score. ${ }^{61}$ At the population level, the DBI tool could be used as a quality indicator to guide policy to improve prescribing and optimise clinical outcomes in older people. ${ }^{15}$

\section{Conclusions}

In conclusion, this large population-based study has shown that there is a high prevalence of use of medications with anticholinergic and sedative effects among Irish community-dwelling older people, particularly in females and those with multiple comorbidities. The high use of low-dose codeine/paracetamol combination products, Z-drugs and benzodiazepines, suggests that there are opportunities for deprescribing in this population. The consensus list of DBI medications developed may be of use in future studies using the DBI tool. Future research should focus on examining the impact of DBI on important health outcomes in older Irish patients, and developing interventions to reduce the inappropriate use of DBI medications in this vulnerable patient population.

Acknowledgements We thank the HSE-PCRS for supplying the data on which the study was based. Funding from the Health Research Board in Ireland (RL-20151579) supported the research.

Contributors CJB and KB conceived and designed the study. CJB, CW, DJW and $C R$ contributed to development of the DBI medication list. KB accessed the data (HSE-PCRS). KB, CJB and CC performed the analysis and interpreted the results. CJB wrote the manuscript. All authors critically revised the manuscript and approved the final version.

Funding This work was supported by the Health Research Board in Ireland (grant code RL-2015-1579).

Disclaimer The funder had no role in the conduct of the study.

Competing interests None declared.

Patient consent Not required.

Ethics approval The anonymised data in this study were exempt from review by an institutional review board.

Provenance and peer review Not commissioned; externally peer reviewed. Data sharing statement № additional data are available.

Open access This is an open access article distributed in accordance with the Creative Commons Attribution Non Commercial (CC BY-NC 4.0) license, which permits others to distribute, remix, adapt, build upon this work non-commercially, and license their derivative works on different terms, provided the original work is properly cited, appropriate credit is given, any changes made indicated, and the use is non-commercial. See:@http:// creativecommons.org/licenses/by-nc/4.0/. 


\section{REFERENCES}

1. Sumukadas D, McMurdo ME, Mangoni AA, et al. Temporal trends in anticholinergic medication prescription in older people: repeated cross-sectional analysis of population prescribing data. Age Ageing 2014;43:515-21.

2. Kouladjian L, Gnjidic D, Chen TF, et al. Drug Burden Index in older adults: theoretical and practical issues. Clin Interv Aging 2014;9:1503-15.

3. Han L, Agostini JV, Allore HG. Cumulative anticholinergic exposure is associated with poor memory and executive function in older men. $J$ Am Geriatr Soc 2008;56:2203-10.

4. Fox C, Richardson K, Maidment ID, et al. Anticholinergic medication use and cognitive impairment in the older population: the medical research council cognitive function and ageing study. J Am Geriatr Soc 2011;59:1477-83.

5. Taipale HT, Hartikainen S, Bell JS. A comparison of four methods to quantify the cumulative effect of taking multiple drugs with sedative properties. Am J Geriatr Pharmacother 2010;8:460-71.

6. Cutson TM, Gray SL, Hughes MA, et al. Effect of a single dose of diazepam on balance measures in older people. J Am Geriatr Soc 1997;45:435-40.

7. Gnjidic D, Cumming RG, Le Couteur DG, et al. Drug Burden Index and physical function in older Australian men. Br J Clin Pharmacol 2009;68:97-105.

8. Tinetti ME, Speechley M, Ginter SF. Risk factors for falls among elderly persons living in the community. $N$ Engl $\mathrm{J}$ Med 1988;319:1701-7.

9. Landi F, Onder G, Cesari M, et al. Psychotropic medications and risk for falls among community-dwelling frail older people: an observational study. J Gerontol A Biol Sci Med Sci 2005;60:622-6.

10. Landi F, Russo A, Liperoti R, et al. Anticholinergic drugs and physical function among frail elderly population. Clin Pharmacol Ther 2007;81:235-41.

11. Gray SL, LaCroix AZ, Hanlon JT, et al. Benzodiazepine use and physical disability in community-dwelling older adults. J Am Geriatr Soc 2006;54:224-30.

12. Carrière I, Fourrier-Reglat $A$, Dartigues JF, et al. Drugs with anticholinergic properties, cognitive decline, and dementia in an elderly general population: the 3-city study. Arch Intern Med 2009;169:1317-24.

13. Hanlon JT, Horner RD, Schmader KE, et al. Benzodiazepine use and cognitive function among community-dwelling elderly. Clin Pharmacol Ther 1998;64:684-92.

14. Glass J, Lanctôt KL, Herrmann N, et al. Sedative hypnotics in older people with insomnia: meta-analysis of risks and benefits. BMJ 2005;331:1169.

15. Nishtala PS, Narayan SW, Wang T, et al. Associations of drug burden index with falls, general practitioner visits, and mortality in older people. Pharmacoepidemiol Drug Saf 2014;23:753-8.

16. Campbell AJ, Robertson MC, Gardner MM, et al. Psychotropic medication withdrawal and a home-based exercise program to prevent falls: a randomized, controlled trial. J Am Geriatr Soc 1999;47:850-3.

17. Cumming RG, Le Couteur DG. Benzodiazepines and risk of hip fractures in older people: a review of the evidence. CNS Drugs 2003;17:825-37.

18. Garfinkel D, Mangin D. Feasibility study of a systematic approach for discontinuation of multiple medications in older adults: addressing polypharmacy. Arch Intern Med 2010;170:1648-54.

19. Hilmer SN, Mager DE, Simonsick EM, et al. A drug burden index to define the functional burden of medications in older people. Arch Intern Med 2007;167:781-7.

20. Hilmer SN, Mager DE, Simonsick EM, et al. Drug burden index score and functional decline in older people. Am J Med 2009;122:1142-9.

21. Gnjidic D, Hilmer SN, Blyth FM, et al. High-risk prescribing and incidence of frailty among older community-dwelling men. Clin Pharmacol Ther 2012;91:521-8.

22. Wilson NM, Hilmer SN, March LM, et al. Associations between drug burden index and falls in older people in residential aged care. J Am Geriatr Soc 2011;59:875-80.

23. Gnjidic D, Hilmer SN, Hartikainen S, et al. Impact of high risk drug use on hospitalization and mortality in older people with and without Alzheimer's disease: a national population cohort study. PLoS One 2014;9:e83224

24. Health Service Executive. Primary care reimbursement service: statistical analysis of claims and payments. Dublin, Ireland: Health Service Executive, 2015.

25. Central Statistics Office. Census of population 2016 - profile 3 an age profile of Ireland. http://www.cso.ie/en/statistics/ (accessed 1 Dec 2017).
26. WHO Collaborating Centre for Drug Statistics Methodology. ATC/ DDD Index. 2017. https://www.whocc.no/atc ddd index/

27. Medicines.ie. Medicines information online - summary of product characteristics. http://www.medicines.ie/ (accessed Oct 2017).

28. Medicines.org.uk. Electronic Medicines Compendium (eMC). http:// www.medicines.org.uk/emc/ (accessed Oct 2017).

29. Medicines Complete. British National Formulary (BNF). 2017. https:// www.medicinescomplete.com/mc/bnf/current/search.htm?q=bnf (accessed Oct 2017).

30. Medicines Complete. Martindale: The Complete Drug Reference. 2017 https://www.medicinescomplete.com/mc/martindale/ (accessed Oct 2017).

31. Semla TP, Beizer JL, Higbee MD. Geriatric dosage handbook: Including clinical recommendations and monitoring guidelines (21st Edition. Hudson, Ohio: Lexicomp, 2016.

32. Ailabouni N, Mangin D, Nishtala PS. Deprescribing anticholinergic and sedative medicines: protocol for a Feasibility Trial (DEFEATpolypharmacy) in residential aged care facilities. BMJ Open 2017;7:e013800.

33. Cahir C, Fahey T, Teeling M, et al. Potentially inappropriate prescribing and cost outcomes for older people: a national population study. Br J Clin Pharmacol 2010;69:543-52.

34. Byrne CJ, Cahir C, Curran C, et al. High-risk prescribing in an Irish primary care population: trends and variation. $\mathrm{Br} J$ Clin Pharmacol 2017;83:2821-30.

35. Bosboom PR, Alfonso H, Almeida OP, et al. Use of potentially harmful medications and health-related quality of life among people with dementia living in residential aged care facilities. Dement Geriatr Cogn Dis Extra 2012;2:361-71.

36. Gnjidic D, Bell JS, Hilmer SN, et al. Drug burden index associated with function in community-dwelling older people in Finland: a crosssectional study. Ann Med 2012;44:458-67.

37. Simoni-Wastila L. Gender and psychotropic drug use. Med Care 1998;36:88-94.

38. Tu K, Mamdani MM, Hux JE, et al. Progressive trends in the prevalence of benzodiazepine prescribing in older people in Ontario, Canada. J Am Geriatr Soc 2001;49:1341-5.

39. Goulding MR. Inappropriate medication prescribing for elderly ambulatory care patients. Arch Intern Med 2004;164:305-12.

40. Bierman AS, Pugh MJ, Dhalla I, et al. Sex differences in inappropriate prescribing among elderly veterans. Am J Geriatr Pharmacother 2007;5:147-61.

41. Cafferata GL, Meyers SM. Pathways to psychotropic drugs. Understanding the basis of gender differences. Med Care 1990;28:285-300.

42. van der Waals FW, Mohrs J, Foets M. Sex differences among recipients of benzodiazepines in Dutch general practice. BMJ 1993;307:363-6.

43. Wilson NM, Hilmer SN, March LM, et al. Associations between drug burden index and physical function in older people in residential aged care facilities. Age Ageing 2010;39:503-7.

44. Gnjidic D, Le Couteur DG, Abernethy DR, et al. Drug burden index and beers criteria: impact on functional outcomes in older people living in self-care retirement villages. J Clin Pharmacol 2012;52:258-65.

45. Cao YJ, Mager DE, Simonsick EM, et al. Physical and cognitive performance and burden of anticholinergics, sedatives, and ACE inhibitors in older women. Clin Pharmacol Ther 2008;83:422-9.

46. Shaheed CA, Maher CG, McLachlan AJ. Investigating the efficacy and safety of over-the-counter codeine combination analgesics for pain and codeine based antitussives. Woden, Australia: Government of Australia, Department of Health, Thereapeutic Goods Administration, 2016.

47. de Craen AJ, Di Giulio G, Lampe-Schoenmaeckers JE, et al. Analgesic efficacy and safety of paracetamol-codeine combinations versus paracetamol alone: a systematic review. BMJ 1996;313:321-5.

48. Robinson GM, Robinson S, McCarthy P, et al. Misuse of over-thecounter codeine-containing analgesics: dependence and other adverse effects. N Z Med J 2010;123:59-64.

49. Ferner RE, Beard K. Over the counter medicines: proceed with caution. BMJ 2008;336:694-6.

50. Moore RA, McQuay HJ. Prevalence of opioid adverse events in chronic non-malignant pain: systematic review of randomised trials of oral opioids. Arthritis Res Ther 2005;7:R1046-51.

51. Shorr RI, Griffin MR, Daugherty JR, et al. Opioid analgesics and the risk of hip fracture in the elderly: codeine and propoxyphene. $J$ Gerontol 1992;47:M111-5.

52. McLachlan AJ, Bath S, Naganathan V, et al. Clinical pharmacology of analgesic medicines in older people: impact of frailty and cognitive impairment. Br J Clin Pharmacol 2011;71:351-64. 
53. Huerta C, Abbing-Karahagopian V, Requena G, et al. Exposure to benzodiazepines (anxiolytics, hypnotics and related drugs) in seven European electronic healthcare databases: a cross-national descriptive study from the PROTECT-EU Project. Pharmacoepidemiol Drug Saf 2016;25(Suppl 1):56-65.

54. Bénard-Laribière A, Noize P, Pambrun E, et al. Trends in incident use of benzodiazepines and Z-drugs in France from 2006 to 2012: a population-based study. Pharmacoepidemiol Drug Saf 2017;26:162-9.

55. Davidson JR, Zhang W, Connor KM, et al. A psychopharmacological treatment algorithm for generalised anxiety disorder (GAD). $J$ Psychopharmacol 2010;24:3-26.

56. Bourgeois J, Elseviers MM, Van Bortel L, et al. Feasibility of discontinuing chronic benzodiazepine use in nursing home residents: a pilot study. Eur J Clin Pharmacol 2014;70:1251-60.

57. Curran HV, Collins R, Fletcher S, et al. Older adults and withdrawal from benzodiazepine hypnotics in general practice: effects on cognitive function, sleep, mood and quality of life. Psychol Med 2003;33:1223-37.

58. Tsunoda K, Uchida H, Suzuki T, et al. Effects of discontinuing benzodiazepine-derivative hypnotics on postural sway and cognitive functions in the elderly. Int $J$ Geriatr Psychiatry 2010;25:1259-65.

59. Gould RL, Coulson MC, Patel N, et al. Interventions for reducing benzodiazepine use in older people: meta-analysis of randomised controlled trials. Br J Psychiatry 2014;204:98-107.

60. Wouters $\mathrm{H}$, van der Meer H, Taxis K. Quantification of anticholinergic and sedative drug load with the Drug Burden Index: a review of outcomes and methodological quality of studies. Eur J Clin Pharmacol 2017;73:257-66.

61. Nishtala PS, Hilmer SN, McLachlan AJ, et al. Impact of residential medication management reviews on drug burden index in aged-care homes: a retrospective analysis. Drugs Aging 2009;26:677-86 